\title{
Factors Affecting Quality of Life among Post-Stroke Patients in the Sub-Himalayan Region
}

\author{
Tarannum Ahmed ${ }^{1} \quad$ Tamanna $^{1}$ Rajesh Kumar ${ }^{1, \odot}$ Yogesh Bahurupi $^{2}$ \\ ${ }^{1}$ College of Nursing, All India Institute of Medical Sciences, \\ Rishikesh, Uttarakhand, India \\ ${ }^{2}$ Department of Community \& Family Medicine, All India Institute of \\ Medical Sciences, Rishikesh, Uttarakhand, India

\begin{abstract}
Address for correspondence Rajesh Kumar, PhD, BSN, MSN, College of Nursing, All India Institute of Medical Sciences, Rishikesh, Uttarakhand 249203, India (e-mail: rajesh.nur@aiimsrishikesh.edu.in).
\end{abstract}

J Neurosci Rural Pract 2020;11:616-622

\begin{abstract}
Background Stroke is one of the most debilitating conditions contributing to significant disability and death globally. Identifying risk factors for quality of life (QoL) will enable to improve home-based rehabilitation in post-stroke phase.

Objective This study was aimed to identify the risk factors of QoL in stroke patients in the sub-Himalayan region.

Materials and Methods A cross-sectional hospital-based study assessed the QoL among stroke patients within a week after the onset of acute stroke and then re-evaluated at 3 months. World Health Organization QoL-BREF, Beck Depression Inventory, the Barthel Index, and Montreal Cognitive Assessment (MOCA) were used to seek data on QoL, depression, cognitive, and functional dependence status, respectively. Appropriate statistics were used to compute the results.

Results In total, 129 stroke patients recruited, out of which 102 returned to a 3-month follow-up. QoL, MOCA, disability index, and depression score were compared using Wilcoxon Singed-rank test. In multivariate analysis, depression and disability together predicted $60 \%$ of the variance for physical QoL $(p<0.0001)$. Similarly,

Keywords

- poststroke

- depression

- disability

- cognitive changes

- quality of life poststroke depression and disability together predicted $61 \%$ of the variance for psychological QoL $(p<0.0001)$ in stroke patients.

Conclusion Findings indicated that depression and disability are leading risk factors of QoL in stroke patients. Early identification of poststroke depression and functional dependence status is, therefore, essential to devise screening procedure and to develop targeted intervention to improve rehabilitation outcomes.
\end{abstract}

\section{Introduction}

Stroke is a significant cause of death and disability around the globe. ${ }^{1}$ However, the use of advanced medical technology significantly reduced the case fatality in the acute stage of stroke. Still, maintaining or improving optimal quality of life (QoL) of stroke patients remains a challenge for health professionals in developing countries, including India. Previous studies reported numerous risk factors associated with compromised QoL in stroke survivors. Gender, age, disability, ${ }^{2}$ the severity of stroke, ${ }^{3}$ depression, ${ }^{4-11}$ hypertension, dependency status, poor socioeconomic status, unemployment status, ${ }^{3,12,13}$ and cognitive impairment ${ }^{3}$ were reported as accurate predictors of QoL among stroke survivors.
It was highlighted that post-stroke depression associated with higher cognitive impairment, ${ }^{9,14}$ mortality, increase vulnerability to fall, ${ }^{13}$ higher disability, and poor rehabilitation outcome. ${ }^{15,16}$ Further, a bunch of literature mentioned the negative impact of depression on post-stroke rehabilitation and outcome. However, a paucity of literature draws attention to identify the risk factors of QoL in rehabilitation outcome. The study aim is to predict the risk factors of QoL in post-stroke patients.

\section{Materials and Methods}

A prospective hospital-based study conducted by enrolling 129 stroke patients within the first week of stroke onset. 
Study participants were recruited in the study between July 2019 to January 2020 and were re-evaluated $(n=102)$ at 3 months of follow-up. We included the patients diagnosed by computed tomography (CT)/magnetic resonance imaging (MRI) for ischemic or hemorrhagic stroke in the age group $>18$ years. Patients with complaints of aneurysm rupture, arteriovenous malformation, and other comorbid conditions such as diagnosed depression, dementia, brain injury, and unable to communicate in Hindi/English language due to aphasia, and on anticoagulation agents, were excluded from the study. The Institutional Ethics Committee (IEC) approved the study (All India Institute of Medical Sciences/IEC/19/1159). Data are transformed into Microsoft Excel sheet and analyzed by using SPPS version 23.0. Frequency, percentage, and mean \pm standard deviation were used for descriptive information. Data distribution was considered for the application of inferential statistics. Pearson's correlation and linear regression and multivariate regression analysis were applied to assess the relationship with QoL.

Table 1 Demographics of study population at baseline $(n=129)$

\begin{tabular}{|c|c|c|}
\hline Variables & Categories & $\begin{array}{l}f(\%) \\
(n=129)\end{array}$ \\
\hline Age $(y)$ & Mean \pm SD & $53.84 \pm 14.3$ \\
\hline \multirow[t]{2}{*}{ Gender } & Male & $86(66.7)$ \\
\hline & Female & $43(33.3)$ \\
\hline \multirow[t]{2}{*}{ Occupation } & Employed & $31(24)$ \\
\hline & Unemployed & $98(76)$ \\
\hline \multirow[t]{2}{*}{ Marital status } & Unmarried & $10(7.7)$ \\
\hline & Married & $119(92.2)$ \\
\hline \multirow[t]{4}{*}{ Education } & Informal education & $64(49.6)$ \\
\hline & Up to 10th passed & $21(16.3)$ \\
\hline & Up to 12 th passed & $22(17.1)$ \\
\hline & Graduate and above & $22(17.0)$ \\
\hline \multirow[t]{2}{*}{ Type of family } & Joint family & $76(58.9)$ \\
\hline & Nuclear family & $53(41.1)$ \\
\hline \multirow[t]{3}{*}{ Dependency on family } & Not dependent & $47(36.4)$ \\
\hline & Partial dependent & $53(41.1)$ \\
\hline & Completely dependent & $29(22.5)$ \\
\hline \multicolumn{3}{|l|}{ Stroke characteristics } \\
\hline Family H/O Stroke/TIA & Yes & 15 (11.6) \\
\hline \multirow[t]{2}{*}{ Types of stroke } & Ischemic & $122(94.6)$ \\
\hline & Hemorrhagic & $07(5.4)$ \\
\hline \multirow[t]{2}{*}{ GCS } & $8-12$ & $100(77.5)$ \\
\hline & $>13$ & $29(22.5)$ \\
\hline \multicolumn{3}{|l|}{ Comorbid characteristics } \\
\hline $\mathrm{H} / \mathrm{O} \mathrm{HTN}$ & Yes & $97(75.2)$ \\
\hline $\mathrm{H} / \mathrm{O} \mathrm{MI}$ & Yes & $11(8.5)$ \\
\hline $\mathrm{H} / \mathrm{O}$ cholesterol & Yes & $15(11.6)$ \\
\hline $\mathrm{H} / \mathrm{O}$ diabetes mellitus & Yes & $36(27.9 \%)$ \\
\hline $\mathrm{H} / \mathrm{O}$ stroke or TIAs & Yes & $114(88.4 \%)$ \\
\hline \multirow[t]{2}{*}{ Types of smoking } & Smoking & $42(32.5)$ \\
\hline & Smokeless & $21(16.4)$ \\
\hline \multirow[t]{2}{*}{ Number of Cigarettes/bidi/day } & $<6$ & $15(11.6)$ \\
\hline & $\geq 6$ & $44(34.1)$ \\
\hline MOCA, mean (SD) & \multicolumn{2}{|l|}{$18.16 \pm 5.12$} \\
\hline BI, mean (SD) & \multicolumn{2}{|l|}{$15.10 \pm 5.24$} \\
\hline $\mathrm{BDI}$, mean (SD) & \multicolumn{2}{|l|}{$20.72 \pm 11.17$} \\
\hline
\end{tabular}

Abbreviations: BDI, Beck Depression Inventory; BI, Barthel Index; GCS, Glasgow Coma Scale; H/O, history of; HTN, hypertension; MI, myocardial infarction; MOCA, montreal cognitive assessment; QoL, quality of life; SD, standard deviation; TIA, transient ischemic attack. 


\section{Demographic and Clinical Variables}

Demographic information (e.g., age, gender, occupation, education, employment status, and marital status), family history of stroke/transient ischemic attacks (TIAs), types of stroke, myocardial infarction, hypertension, diabetes mellitus, cholesterol, types of smoking, and number of cigarettes/bidi.

World Health Organization Quality of Life(WHOQoL-BREF): The World Health Organization devise the questionnaire to measure the QoL. It is 26 items self-administered 5 points Likert scale in which items are categorized to measure physical aspects, psychological status, social affairs, and environmental context of an individual. Converting raw score to a 0 to 100 scale gives a measurement of QoL in the individual domain, with a higher score recommend a better QoL. The WHOQoL-BREF is widely used for similar population and translated in a different language for use, including Hindi. ${ }^{17}$

Beck Depression Inventory (BDI): Aaron Beck (1961) developed the scale to determine the extent of severity of depression. The self-rated scale asked the participant to rate their depression symptoms on a 4-point spectrum, with a total score of 0 to 63 . Overall score further subdivided into different categories to determine the degree of depression. ${ }^{18} \mathrm{~A}$ Hindi version of the scale is used for the present study. ${ }^{19}$

Montreal Cognitive Assessment (MOCA): It is a brief standardized screening instrument used for cognitive impairment. ${ }^{20}$ The MOCA measures several domains, including attention, naming, language, delayed recall, orientation, and visuospatial. It has a total score range of 0 to 30 . One extra point is added to individual received education $<12$ years. This tool is widely used for cognitive assessment in earlier studies and found reliable and valid for similar sample. ${ }^{21} \mathrm{~A}$ score $<26$ indicates cognitive impairment.

The Barthel Index (BI): This scale is used to measure the extent to which one individual can perform his daily activities independently, that is, feeding, dressing, bathing, grooming, toilet use, bowel-bladder care, stair climbing, ambulation, and chair transfer. A maximum score of 100 represents a patient full independent and 0 indicates a state of total dependence. ${ }^{22,23}$ The $\mathrm{BI}$ is considered reliable disability index to use for stroke population. ${ }^{24}$

\section{Results}

A total of 129 patients enrolled in the study, and only 102 completed the 3-month follow-up. In total, $66.7 \%$ were males and $33.3 \%$ were females with a mean age of $54( \pm 14.3)$ years. Only $24 \%$ of patients were employed and married (92.2\%), respectively. Similarly, in terms of education, $49.6 \%$ of patients were never attended formal schooling in contrast to $17 \%$, educated up to graduation or more.

More than $50 \%$ of the patient belonged to the joint family (58.9\%) and had family members for support in the care of their patients (22.5\%). In terms of stroke-related information, the majority (94.6\%) of patients had an ischemic stroke and reported GCS of 8 to 12 at the time of admission (77.5\%), 75\% of patients said a history of hypertension, followed by myocardial infarction (8.5\%), high cholesterol (11.6\%), diabetes mellitus (27.9\%), and stroke or TIA (88.4\%).

In terms of the history of smoking, $32.5 \%$ of patients were using one or another form of tobacco products, while $16.4 \%$ were using smokeless tobacco products. Total $34.1 \%$ of patients were using more than six cigarettes/bidi per day. Baseline score of MOCA was $18.16 \pm 5.12$, BDI was $20.72 \pm 11.17$, and BI score was $15.10 \pm 5.24$ ( Table 1 ).

( - Table 2) represents the finding of an association of various domains of QoL with gender, age, types of stroke, and Glasgow Coma Scale (GCS) score of stroke patients. Older patients ( $>50$ years) shows significant statistical association with environment and social QoL. However, these findings remain nonsignificant for physical and psychological QoL. Further, it is that a higher GCS score at admission reported statistically significant association with better physical,

Table 2 Association of patient characteristics with domains of quality of life

\begin{tabular}{|l|l|l|l|l|}
\hline Variables & Physical QoL & Psychological QoL & Social QoL & Environment QoL \\
\hline $\begin{array}{l}\text { Age }(y) \\
<50 \\
>50\end{array}$ & $\begin{array}{l}460.5 \pm 13.62 \\
47.32 \pm 12.48\end{array}$ & $\begin{array}{l}57.35 \pm 16.17 \\
59.10 \pm 15.27\end{array}$ & $\begin{array}{l}69.10 \pm 10.08 \\
71.35 \pm 9.92\end{array}$ & $50.80 \pm 15.49$ \\
$56.97 \pm 12.48$ \\
\hline$p$-Value & 0.567 & 0.577 & $0.037^{\mathrm{a}}$ & $0.012^{\mathrm{a}}$ \\
\hline $\begin{array}{l}\text { Gender } \\
\text { Male }\end{array}$ & $46.47 \pm 13.96$ & $58.22 \pm 16.73$ & $69.97 \pm 11.11$ & $54.83 \pm 14.63$ \\
Female & $46.67 \pm 9.98$ & $58.87 \pm 12.62$ & $71.67 \pm 6.58$ & $53.87 \pm 12.47$ \\
\hline$p$-Value & 0.777 & 0.905 & 0.721 & 0.941 \\
\hline $\begin{array}{l}\text { Types of stroke } \\
\text { Ischemic } \\
\text { Hemorrhagic }\end{array}$ & $46.82 \pm 13.02$ & $58.49 \pm 15.68$ & $70.29 \pm 10.16$ & $54.17 \pm 14.03$ \\
\hline$p$-Value & $47.00 \pm 1.39$ & $56.50 \pm 14.43$ & $75.00 \pm 0.000$ & $50.50 \pm 14.43$ \\
\hline $\begin{array}{l}\text { GCS } \\
9-12\end{array}$ & 0.927 & 0.797 & 0.510 & 0.554 \\
$\geq 13$ & $44.05 \pm 11.93$ & $55.05 \pm 14.77$ & $69.72 \pm 1.05$ & $0.92 \pm 12.27$ \\
\hline$p$-value & $55.83 \pm 11.89$ & $69.33 \pm 13.13$ & $72.92 \pm 7.49$ & $66.33 \pm 12.89$ \\
\hline
\end{tabular}

Abbreviations: GCS, Glasgow coma scale; QoL, quality of life. ${ }^{\text {a }} p<0.05$. 
psychological, maintaining social relationships, and better adjust to environment QoL domains in the poststroke rehabilitation phase ( - Table 2 ).

- Table 3 represents the status of baseline and 3-months follow-up on depression, functional dependence level, cognitive status, and QoL in stroke patients. Depression, functional dependence, cognitive changes, and all four domains of QoL noticed a statistically significant improvement at 3-month follow-up. (-Table 3) summarized findings on Wilcoxon signed-rank test result.

- Table 4 shows the correlation between the QoL and BDI, MOCA, and the Barthel Index (BI). Findings reveal that depression has a negative relationship with all four domains of QoLphysical, psychological, social, and environment-indicates that patient with higher depression has a poor QoL in stroke rehabilitation. Conversely, MOCA found a significant positive correlation with physical and psychological QoL, which indicates that higher or improved cognition status will enable the patient to manage his physical and psychological health in a better way as compared with their counterparts. Similarly, functional independence index (BI) shows a positive correlation with physical, psychological, and social QoL-suggesting functionally dependent patients have a poor QoL in physical, psychological, and social relationship domains (-Figs. 1-4).

Bivariate linear regression used to detect the predictor of various domains of QoL. The factors show significant association with QoL regression analyses are shown in (-Table 5 ). Depression and cognitive changes were significantly associated with worse physical health, negative psychological consequences, and poor environment adjustment on univariate analysis. Similarly, functional dependence was significantly associated with worse physical, psychological, and social domains of QoL. (- Table 5) summarized the findings on predictors of QOL.

\section{Risk Factor Related to Quality of life: Multivariate Logistic Regression}

The result of analyses to identify independent factors (BDI, $\mathrm{BI}$, and MOCA) that influence QoL are reported in - Table 6. Higher depression and functionally dependent status were reported as a negative factor for the compromised QoL in stroke patients. The regression model reported two predictors (BDI and $\mathrm{BI})$ with $60.4 \%$ of the variance $\left(\mathrm{R}^{2}=0.604\right)$ for

Table 4 Relationship between World Health Organisation Quality of Life and Beck Depression Inventory, Montreal Cognitive Assessment, and Barthel Index

\begin{tabular}{|l|l|l|l|}
\hline Characteristic & Variable & $\boldsymbol{r}$ & $\boldsymbol{p}$-Value \\
\hline Physical QoL & Depression & $-0.729^{\mathrm{a}}$ & $<0.000$ \\
& MOCA & $0.338^{\mathrm{a}}$ & $<0.001$ \\
& $\mathrm{Bl}$ & $0.482^{\mathrm{a}}$ & $<0.000$ \\
\hline Psychological QoL & Depression & $-0.745^{\mathrm{a}}$ & $<0.000$ \\
& MOCA & $0.340^{\mathrm{a}}$ & $<0.000$ \\
& BI & $0.457^{\mathrm{a}}$ & $<0.000$ \\
\hline Social QoL & Depression & -0.029 & 0.773 \\
& MOCA & 0.047 & 0.640 \\
\hline Environment QoL & BI & $0.278^{\mathrm{a}}$ & $<0.005$ \\
& Depression & $-0.617^{\mathrm{a}}$ & $<0.000$ \\
& MOCA & 0.157 & 0.116 \\
& BI & 0.190 & 0.055 \\
\hline
\end{tabular}

Abbreviations: BDI, Beck Depression Inventory; BI, Barthel Index; MOCA, Montreal Cognitive Assessment; QoL, quality of life. ${ }^{\mathrm{a}} \mathrm{p}<0.01$.

Table 3 Summary of Wilcoxon signed-rank test result

\begin{tabular}{|l|l|l|l|l|}
\hline Variables & $\begin{array}{l}\text { Baseline } \\
\text { (Mean } \pm \text { SD) }\end{array}$ & $\begin{array}{l}\text { Follow-up } \\
\text { (Mean } \pm \text { SD) }\end{array}$ & Z-score & $p$-Value \\
\hline BDI Score & $20.72 \pm 11.17$ & $10.62 \pm 9.11$ & -7.856 & $0.0001^{\text {a }}$ \\
\hline MOCA Score & $18.16 \pm 5.12$ & $21.20 \pm 3.61$ & -7.759 & $0.0001^{\text {a }}$ \\
\hline BI Score & $15.10 \pm 5.24$ & $18.47 \pm 3.27$ & -7.59 & $0.0001^{\text {a }}$ \\
\hline Physical QoL & $44.84 \pm 21.57$ & $46.82 \pm 12.88$ & -3.267 & $0.001^{\text {a }}$ \\
\hline Psychological QoL & $43.11 \pm 19.10$ & $58.41 \pm 15.57$ & -7.342 & $0.0001^{\text {a }}$ \\
\hline Social QoL & $62.73 \pm 13.40$ & $70.47 \pm 9.99$ & -5.735 & $0.0001^{\text {a }}$ \\
\hline Environment QoL & $44.86 \pm 14.64$ & $54.55 \pm 13.99$ & -7.136 & $0.0001^{\text {a }}$ \\
\hline
\end{tabular}

Abbreviations: BDI, Beck Depression Inventory; BI, Barthel Index; MOCA, Montreal Cognitive Assessment; QoL, quality of life; SD, standard deviation. ${ }^{\mathrm{a}} \mathrm{p}<0.05$. 


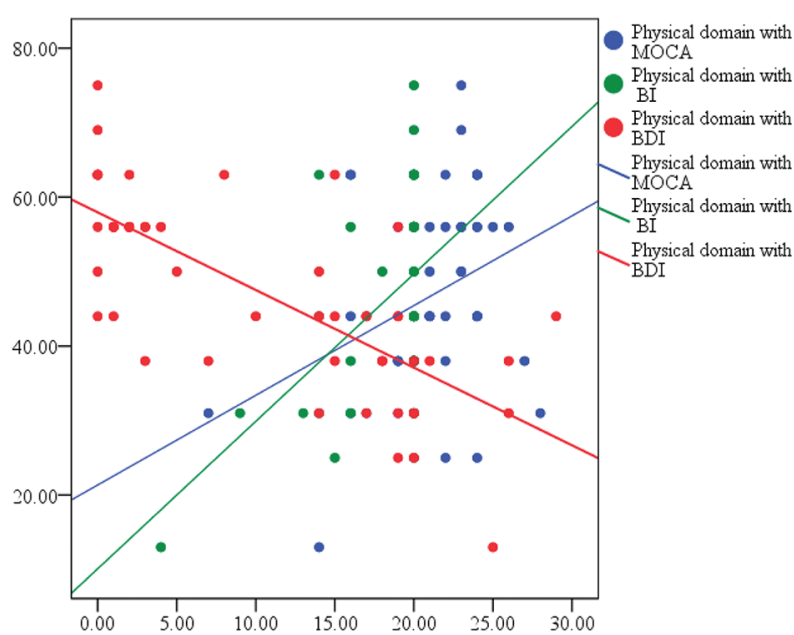

Fig. 1 Correlation coefficient of Beck Depression Inventory, Montrea Cognitive Assessment, and Barthel Index with physical quality of life.

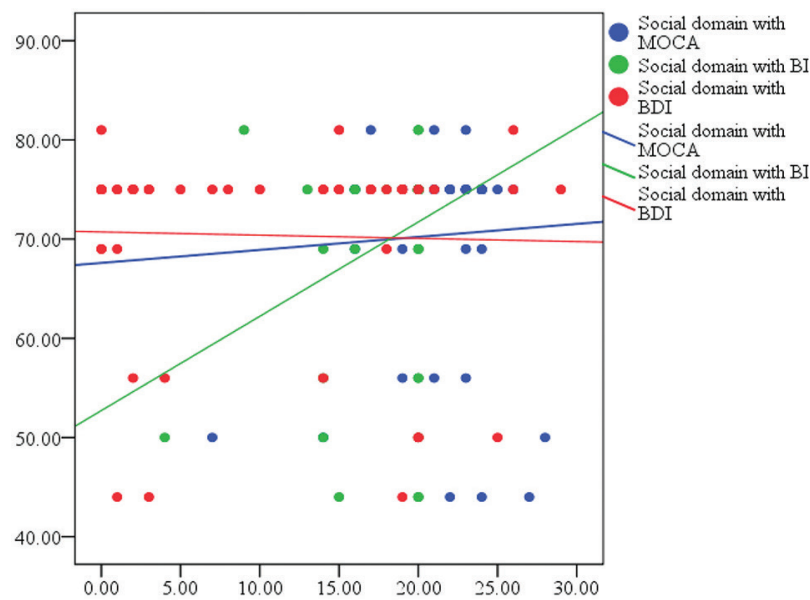

Fig. 2 Correlation coefficient of Beck Depression Inventory, Montreal Cognitive Assessment, and Barthel Index with Social quality of life.

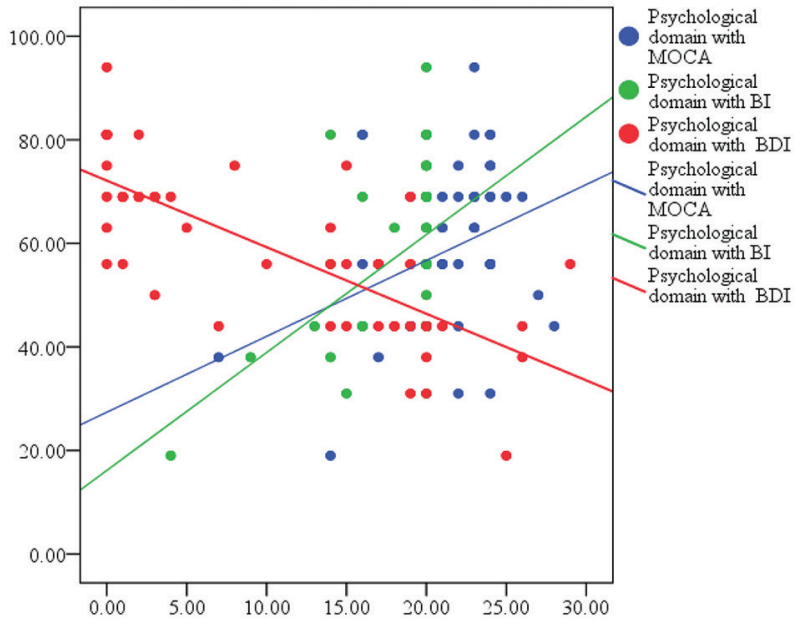

Fig. 3 Correlation coefficient of Beck Depression Inventory, Montreal Cognitive Assessment, and Barthel Index with psychological quality of life.

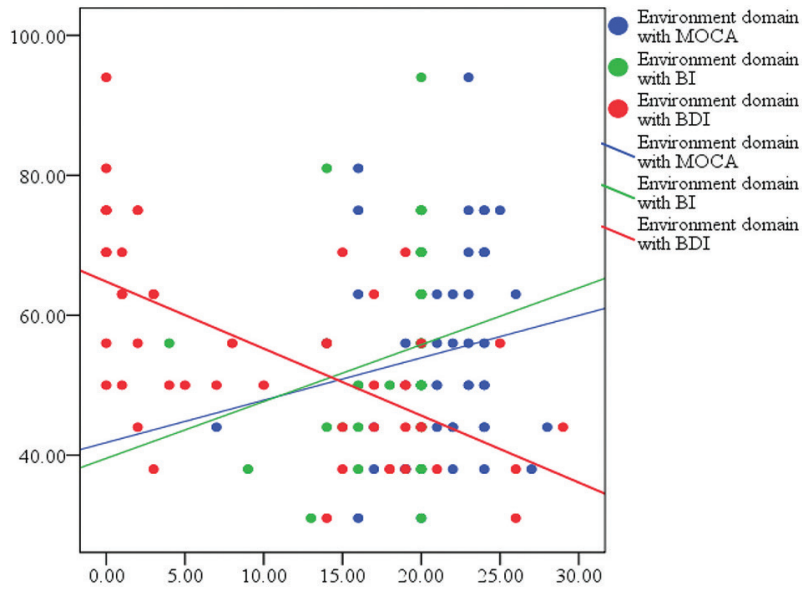

Fig. 4 Correlation coefficient of Beck Depression Inventory, Montreal Cognitive Assessment, and Barthel Index with environment quality of life.

Table 5 Bivariate linear regression for prediction of quality of life

\begin{tabular}{|c|c|c|c|c|c|c|}
\hline \multirow{2}{*}{$\begin{array}{l}\text { Dependent } \\
\text { variable }\end{array}$} & \multirow[t]{2}{*}{ Predictors } & \multirow{2}{*}{$\begin{array}{l}\text { Unstandardized } \\
\text { beta (B) }\end{array}$} & \multicolumn{2}{|c|}{$95 \% \mathrm{Cl}$} & \multirow{2}{*}{$\begin{array}{l}\text { Unadjusted R } \\
\text { Square }\end{array}$} & \multirow[t]{2}{*}{$p$-Value } \\
\hline & & & Lower & Upper & & \\
\hline \multirow[t]{3}{*}{ Physical QoL } & BDI & -1.042 & -1.238 & -0.846 & 0.532 & $0.0001^{\mathrm{a}}$ \\
\hline & MOCA & 1.205 & -0.538 & 1.871 & 0.114 & $0.001^{\mathrm{a}}$ \\
\hline & $\mathrm{BI}$ & 1.896 & -1.211 & 2.581 & 0.232 & $0.0001^{\mathrm{a}}$ \\
\hline \multirow{3}{*}{$\begin{array}{l}\text { Psychological } \\
\text { QoL }\end{array}$} & BDI & -1.286 & -1.517 & -1.055 & 0.555 & $0.0001^{\mathrm{a}}$ \\
\hline & MOCA & 1.466 & 0.661 & 2.271 & 0.116 & $0.0001^{\mathrm{a}}$ \\
\hline & $\mathrm{BI}$ & 2.173 & 1.333 & 3.013 & 0.209 & $0.0001^{\mathrm{a}}$ \\
\hline \multirow[t]{3}{*}{ Social QoL } & $\mathrm{BDI}$ & -0.032 & -0.254 & 0.189 & 0.001 & 0.773 \\
\hline & MOCA & 0.130 & -0.419 & 0.678 & 0.002 & 0.640 \\
\hline & $\mathrm{BI}$ & 0.850 & 0.268 & 1.432 & 0.077 & $0.005^{a}$ \\
\hline \multirow[t]{3}{*}{ Environment QoL } & BDI & -0.957 & -1.202 & -0.713 & 0.381 & $0.0001^{\mathrm{a}}$ \\
\hline & MOCA & 0.607 & -0.152 & 1.367 & 0.025 & 0.116 \\
\hline & $\mathrm{BI}$ & 0.813 & -0.019 & 1.646 & 0.420 & 0.055 \\
\hline
\end{tabular}

Abbreviations: BDI, Beck Depression Inventory; BI, Barthel Index; Cl, confidence interval; MOCA, Montreal Cognitive Assessment; QoL, quality of life. ${ }^{\mathrm{a}} \mathrm{p}<0.05$ 
Table 6 Multivariate logistic regression for quality of life risk factors

\begin{tabular}{|c|c|c|c|c|c|c|}
\hline \multirow[t]{2}{*}{ Characteristics } & \multirow[t]{2}{*}{ Variables } & \multirow{2}{*}{$\begin{array}{l}\text { Unstandardized } \\
\text { beta (B) }\end{array}$} & \multirow[t]{2}{*}{ Beta } & \multicolumn{2}{|c|}{$95 \% \mathrm{Cl}$} & \multirow[t]{2}{*}{$p$-Value } \\
\hline & & & & Lower & Upper & \\
\hline \multirow{3}{*}{$\begin{array}{l}\text { Physical QoL } \\
\text { (R square-0.604) }\end{array}$} & BDI & -0.940 & -0.658 & -1.140 & -0.740 & $0.0001^{\mathrm{a}}$ \\
\hline & MOCA & -0.316 & -0.089 & -0.876 & -0.245 & 0.266 \\
\hline & $\mathrm{Bl}$ & 1.280 & 0.316 & 0.657 & 1.903 & $0.0001^{a}$ \\
\hline \multirow{3}{*}{$\begin{array}{l}\text { Psychological QoL } \\
\text { (R square-0.610) }\end{array}$} & BDI & -1.175 & -0.680 & -1.415 & -0.935 & $0.0001^{a}$ \\
\hline & MOCA & -0.318 & -0.074 & -0.990 & 0.354 & 0.350 \\
\hline & $\mathrm{Bl}$ & 1.356 & 0.277 & 0.608 & 2.103 & $0.001^{\mathrm{a}}$ \\
\hline
\end{tabular}

Abbreviations: dependent variable: physical BDI, Beck Depression Inventory; BI, Barthel Index; $\mathrm{Cl}$, confidence interval; MOCA, Montreal Cognitive Assessment; QoL, quality of life.

${ }^{a} p<0.05$

physical QoL. Similarly, BDI and BI are reported independent predictor for psychological QoL with $61 \%$ variance $\left(R^{2}=0.610\right)$. Other outcomes variables such as cognitive changes (MOCA), age, gender, marital status, education, smoking status, types of family, and dependency status on the family for treatment were not significant. The results are summarized in -Table 6 .

\section{Discussion}

The interface between stroke and depression is extremely complex; the pathophysiological process has not as yet been wholly explicated. Numerous studies identified the risk factors for QoL in post-stroke phase, but an array of inconsistent results depicted relying on the assessment tools, studied the subject, and use of different diagnostic criteria. ${ }^{25}$ Our study explored the risk factors of QoL in stroke patients at 3-month of follow-up in the sub-Himalayan region. Study findings reported a statistically significant difference in BDI, BI, various QoL domains, and MOCA at 3 months-indicating a significant improvement in depression, functional dependence, QoL, and cognitive changes in post-stroke phase.

Previous studies reported similar findings for improvement in depression, cognitive changes, functional dependence, and QoL at a different stage of follow-ups in stroke patients. ${ }^{26-29}$ Similarly, cognitive improvement is reported in post-stroke phase at 6 and 12 weeks after acute stroke. ${ }^{30,31}$ Further, current findings reported a negative relationship of depression with various domains of QoL at 3-month follow-up. These findings are in line with the earlier work reported post-stroke depression as one of the common complications, have a detrimental impact on the QoL, resulting from poor health outcomes and even higher mortality in stroke patients. ${ }^{32,33}$ Many other study findings from India, ${ }^{34}$ Spain, ${ }^{13}$ and Melbourne ${ }^{35}$ also reported consistent results.

Likewise, there is a negative correlation between functional dependence and physical, psychological and social domains of QoL. Some of the previous studies ${ }^{3,36-38}$ are in agreement with our findings reported that being more dependent had worse QoL and poor health outcome among stroke patients. . $^{34,39}$

Further, depression, cognitive changes, and functional dependence $(\mathrm{BI})$ were established risk factors for the poor $\mathrm{QoL}$ in stroke patients. These findings are in agreement with many earlier studies conducted on stroke patients reported depression ${ }^{3,34,36-38}$ and functional dependence ${ }^{34,40-42}$ as valid predictors of QoL in stroke patients.

Limitations of the work benefit attention. Our findings may not be extrapolated to the general stroke population because we excluded the patients with psychiatric comorbidities, depression and anxiety, and cognitive or speech problem. Therefore, it is challenging to say the exact influence of stroke on various domains of QoL. Second, the follow-up time was limited to 3 months only, which further limit tfighe long-term changes in functional dependence, cognitive changes and depression and their subsequent impact on health status or stroke outcome. We did not calculate the sample size for the work; however, a sample toward the higher side is chosen but, still the chance of Type II error may not be excluded. The study comprises a sample from the sub-Himalayan region only, which itself represent a different geographical plot and sociocultural disparities.

Despite these limitations, the study represents close and consistent findings for depression and functional status as accurate predictors for $\mathrm{QoL}$ in stroke patients. These findings remain universal around the globe and could be implicated to the sub-Himalayan region or North Indian Territory, but with a caution to use to the other region of the country.

\section{Conclusion}

There was a significant change in QoL, depression, functional dependence, and cognitive changes in the poststroke period. Post-stroke QoL found dependent on depression, functional dependence, and cognitive status in stroke patients. Still, it is not late to think about devising a scheme for timely screening for post-stroke depression in follow-up and developing the targeted intervention.

\section{Ethical Approval}

This study obtained its permission from AIIMS/ IEC/19/1159.

\section{Funding}

The project was funded as STS project by All India Institute of Medical Sciences (AIIMS) Rishikesh, Uttarakhand 249203. 


\section{Conflict of Interest}

None declared.

\section{References}

1 Yeoh YS, Koh GCH, Tan CS, et al. Health-related quality of life loss associated with first-time stroke. PLoS One 2019;14(1):e0211493

2 Aprile I, Piazzini DB, Bertolini C, et al. Predictive variables on disability and quality of life in stroke outpatients undergoing rehabilitation. Neurol Sci 2006;27(1):40-46

3 Kwa VI, Limburg M, de Haan RJ. The role of cognitive impairment in the quality of life after ischaemic stroke. J Neurol 1996;243(8):599-604

4 Teoh V, Sims J, Milgrom J. Psychosocial predictors of quality of life in a sample of community-dwelling stroke survivors: a longitudinal study. Top Stroke Rehabil 2009;16(2):157-166

5 Srivastava A, Taly AB, Gupta A, Murali T. Post-stroke depression: prevalence and relationship with disability in chronic stroke survivors. Ann Indian Acad Neurol 2010;13(2):123-127

6 White J, Magin P, Attia J, Sturm J, McElduff P, Carter G. Predictors of health-related quality of life in community-dwelling stroke survivors: a cohort study. Fam Pract 2016;33(4):382-387

7 Ramos-Lima MJ, Brasileiro IC, Lima TL, Braga-Neto P. Quality of life after stroke: impact of clinical and sociodemographic factors. Clinics (São Paulo) 2018;73:e418

8 Katona M, Schmidt R, Schupp W, Graessel E. Predictors of health-related quality of life in stroke patients after neurological inpatient rehabilitation: a prospective study. Health Qual Life Outcomes 2015;13(1):58

9 KingRB.Qualityoflifeafterstroke.Stroke1996;27(9):1467-1472

10 Choi-Kwon S, Choi JM, Kwon SU, Kang D-W, Kim JS. Factors that Affect the Quality of Life at 3 Years Post-Stroke. J Clin Neurol 2006;2(1):34-41

11 Li LJ, Yao XM, Guan BY, Chen Q, Zhang N, Wang CX. Persistent depression is a predictor of quality of life in stroke survivors: results from a 5-year follow-up study of a Chinese cohort. Chin Med J (Engl) 2019;132(18):2206-2212

12 Ellis C, Grubaugh AL, Egede LE. Factors associated with SF-12 physical and mental health quality of life scores in adults with stroke. J Stroke Cerebrovasc Dis 2013;22(4):309-317

13 Carod-Artal J, Egido JA, González JL, Varela de Seijas E. Quality of life among stroke survivors evaluated 1 year after stroke: experience of a stroke unit. Stroke 2000;31(12):2995-3000

14 Kauhanen M, Korpelainen JT, Hiltunen P, et al. Poststroke depression correlates with cognitive impairment and neurological deficits. Stroke 1999;30(9):1875-1880

15 Paolucci S. Epidemiology and treatment of post-stroke depression. Neuropsychiatr Dis Treat 2008;4(1):145-154

16 Zhang WN, Pan YH, Wang XY, Zhao Y. A prospective study of the incidence and correlated factors of post-stroke depression in China. PLoS One 2013;8(11):e78981

17 Saxena S, Chandiramani K, Bhargava R; World Health Organization Quality of Life. WHOQOL-Hindi: a questionnaire for assessing quality of life in health care settings in India. Natl Med J India 1998;11(4):160-165

18 Beck AT, Depression: Causes and Treatment. Philadelphia, PA: University of Pennsylvania Press; 2006

19 Jeenger J, Wadhwa S, Mathur DM. Prevalence of depression and anxiety symptoms in first attack myocardial infarction patients of mewar region : a cross sectional study. International Journal of Current Research and Review 2014;06(7):79-85

20 Nasreddine ZS, Phillips NA, Bédirian V, et al. The Montreal Cognitive Assessment, MoCA: a brief screening tool for mild cognitive impairment. J Am Geriatr Soc 2005;53(4):695-699

21 Nijsse B, Visser-Meily JMA, van Mierlo ML, Post MW, de Kort PLM, van Heugten CM. Temporal evolution of poststroke cognitive impairment using the montreal cognitive assessment. Stroke 2017;48(1):98-104

22 Barthel DW. Functional evaluation: the barthel index. Md State Med J 1965;14:61-65

23 Sulter G, Steen C, De Keyser J. Use of the Barthel index and modified Rankin scale in acute stroke trials. Stroke 1999;30(8):1538-1541

24 D'Olhaberriague L, Litvan I, Mitsias P, Mansbach HH. A reappraisal of reliability and validity studies in stroke. Stroke 1996;27(12):2331-2336

25 Zhang Y, Wang C, Sun C, et al. Neural complexity in patients with poststroke depression: a resting EEG study. J Affect Disord 2015;188:310-318

26 Lincoln NB, Brinkmann N, Cunningham S, et al. Anxiety and depression after stroke: a 5 year follow-up. Disabil Rehabil 2013;35(2):140-145

27 Yeoh YS, Koh GC, Tan CS, et al. Can acute clinical outcomes predict health-related quality of life after stroke: a oneyear prospective study of stroke survivors. Health Qual Life Outcomes 2018;16(1):221

28 Sivakumar L, Kate M, Jeerakathil T, Camicioli R, Buck B, Butcher K. Serial montreal cognitive assessments demonstrate reversible cognitive impairment in patients with acute transient ischemic attack and minor stroke. Stroke 2014;45(6):1709-1715

29 Paolucci S, Iosa M, Coiro P, et al. Post-stroke depression increases disability more than $15 \%$ in ischemic stroke survivors: case-control study. Front Neurol 2019;10(AUG) :926

30 Fan QY, Qu QM, Zhang H, Liu JJ, Guo F, Qiao J. [The evolution of cognition and its influence factors after stroke]. Zhonghua Nei Ke Za Zhi 2011;50(9):750-753

31 Ballard C, Rowan E, Stephens S, Kalaria R, Kenny RA, Improvements and decline in cognitive function among dementia-free stroke survivors $>75$ years of age2003;34(10):2440-2444

32 Robinson RG, Jorge RE. Post-stroke depression: a review. Am J Psychiatry 2016;173(3):221-231

33 Nickel A, Thomalla G. Post-stroke depression: impact of lesion location and methodological limitations-a topical review. Front Neurol 2017;8(SEP) :498

34 Raju RS, Sarma PS, Pandian JD. Psychosocial problems, quality of life, and functional independence among Indian stroke survivors. Stroke 2010;41(12):2932-2937

35 Sturm JW, Donnan GA, Dewey HM, et al. quality of life after stroke: the North East Melbourne Stroke Incidence Study (NEMESIS) Stroke 2004;35(10):2340-2345

36 Clarke P, Marshall V, Black SE, Colantonio A. Well-being after stroke in Canadian seniors: findings from the Canadian Study of Health and Aging. Stroke 2002;33(4):1016-1021

37 Kim P, Warren S, Madill H, Hadley M. Quality of life of stroke survivors. Qual Life Res 1999;8(4):293-301

38 McEwen S, Mayo N, Wood-Dauphinee S. Inferring quality of life from performance-based assessments. Disabil Rehabil 2000;22(10):456-463

39 Das SK, Banerjee TK, Biswas A, et al. A prospective community-based study of stroke in Kolkata, India. Stroke 2007;38(3):906-910

40 Ahlsiö B, Britton M, Murray V, Theorell T. Disablement and quality of life after stroke. Stroke 1984;15(5):886-890

41 Duncan PW, Samsa GP, Weinberger M, et al. Health status of individuals with mild stroke. Stroke 1997;28(4):740-745

42 Sturm JW, Donnan GA, Dewey HM, Macdonell RAL, Gilligan AK, Thrift AG. Determinants of handicap after stroke: the North East Melbourne Stroke Incidence Study (NEMESIS) Stroke 2004;35(3):715-720 